$\overbrace{\text { STpaul's }}$ FOUNDATION

\title{
Patient Perspectives on Financial Barriers to Home Dialysis Training in BC and Yukon: A Qualitative Survey
}

A. Cunningham ${ }^{1}$, A. Giustino ${ }^{1}$, D. Prchal' ${ }^{1}$, M. Beaulieu ${ }^{1}$

'Division of Nephrology, Department of Medicine, University of British Columbia

\section{BACKGROUND}

- Home modalities offer advantages over in-centre dialysis, including reduced overall health care spending.

- Patients face significant out-of-pocket costs to train at St Paul's Hospital if they live outside the Lower Mainland.

- BCPRA assists with equipment and utilities, but not travel or accommodation costs related to training. Government financial support varies across provinces and health authorities.

- A recent Kidney Foundation survey reported that $50 \%$ of patients' household income decreased after commencing dialysis, and $41 \%$ were below the Canadian low-income cutoff. - The reported annual out-of-pocket costs ranged from $\$ 1400-2500$ depending on dialysis modality.

- The report recommended increasing efforts to subsidize transportation costs and expand access to travel grants, especially for rural areas.

- Patients and their families face financial challenges as income decreases and incurred costs increase. - This can create a financial burden and a barrier to dialysis access, particularly for those of low socioeconomic status.

- Societal costs of CKD are high due to lost work productivity costs to disability insurance, and Canadian pension plan payouts in excess of $\$ 200$ million per year.

\section{OBJECTIVES}

This study aims to understand patient perspectives on the costs incurred for home dialysis training in $\mathrm{BC}$ and Yukon.

\section{METHODS}

- Letters of invitation were sent to 32 patients who have completed training in a home-based method of dialysis and are currently followed by the kidney program at St. Paul's Hospital.

- Patients were invited to complete a telephone survey which included demographic information, open, and closed-ended questions related to the costs they experienced while training. - Each telephone interview was transcribed verbatim, analyzed and emergent themes were identified from the data including representative quotes.

- Participation in the study was voluntary. Informed consent was obtained at the beginning of each interview and in writing. - Ethics approval was obtained from the Providence Health Care Research Ethics Board.

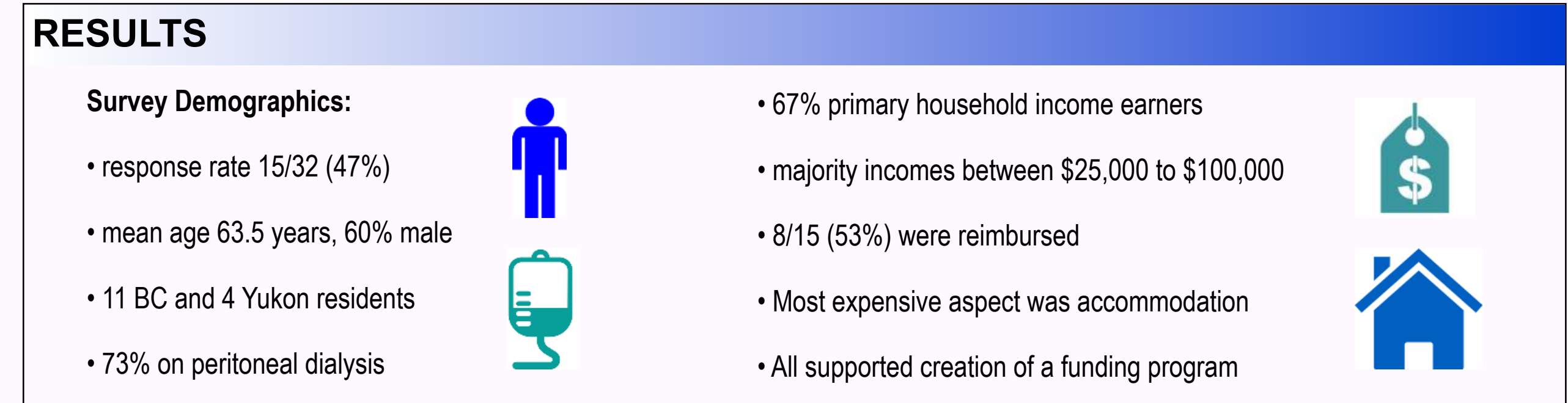

\section{Fig. 1: Survey Participant Locations}

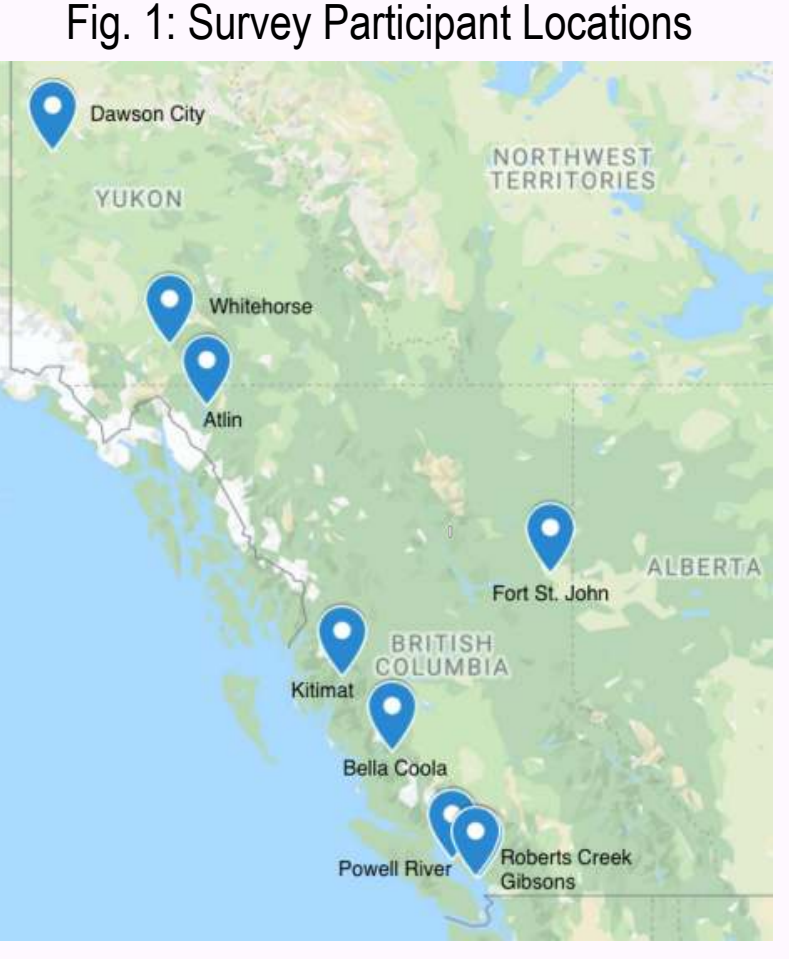

Fig. 2: Which would best describe your experience with training costs?

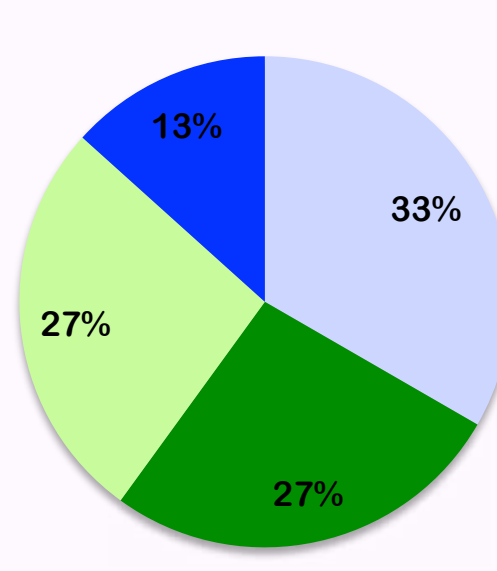

A. Costs were not a barrier to my selection of home modalities B. Costs were a burden for my household, but we were able to manage C. Family or others helped me cover costs

D. Costs related to my training created a financial hardship for me

Representative Quotes:

When you chose your current dialysis method, were costs for training a factor in your decision? - No, not costs per se, no. I didn't really have a choice.

What out-of-pocket costs did you incur for your training?

- We stayed in a hotel right next door to hospital. \$4200 cost. We had to pay out of pocket.

- I found a place to rent...travel money to and from hospital, taxi money and living costs and hard to set up a new place to live in.

Would financial assistance for training have been a benefit for you?

- Yes for housing because it's huge. I was absolutely blown away (by costs).

- Anything would be good... I was very lucky everyone donated money. I don't know what I would have done without family support. - By the time we were down going to Vancouver for two treatments. We were broke and maxed out our credit cards. MHSD did help us find a place for home hemo training and a little for gas and food $\$ 150$ for five weeks. So it got us started.

Were you reimbursed for any out-of-pocket costs related to your training?

- They (Yukon government) pay airline ticket and reimburse $\$ 75$ per day.

- Only travel reimbursed $\$ 30$ for accommodation was the only benefit we got. It comes out of pocket and it still comes out of pocket.

Would you recommend the creation of a program to support patients with the out-of-pocket costs of training? - If I had to pay everything myself I never would be able to afford it. I would have probably strapped together the money...

- The accommodation is often the biggest barrier, if there's some way it can be offset.

\section{CONCLUSION \& NEXT STEPS}

- Our patients incur a significant personal cost during the training period for peritoneal dialysis and home hemodialysis, including transportation, food, accommodation, and other expenses, as well as lost income.

- Reducing the financial burden of training for patients outside urban centres has important implications for increasing uptake of home modalities.

- There is potential to expand the use of simulation to assist dialysis training, though this would not fully replace the need for travel.

-We have secured funding for one patient to train in the Vancouver area. This includes:

-accommodation for PD tube insertion (3 nights)

-accommodation for 2 weeks of training (12 nights)

one return flight

total amount: $\$ 1875.17$

- Moving forward, we plan to continue with the pilot project of reimbursement for SPH patients living within Vancouver Coastal Health region, greater than $50 \mathrm{~km}$ outside the city.

\section{ACKNOWLEDGEMENTS}

We thank the St. Paul's Foundation for their generous support in funding the pilot program.

\section{REFERENCES}

1. The Kidney Foundation of Canada. The burden of out-ofpocket costs for Canadians with kidney failure. https://www.kidney.ca/burden. September 2018 2. Manns B, Hemmelgarn B, Tonelli M, et al. The cost of care for people with chronic kidney disease. Can J Kidney Health Dis 2019; 6: 1-11

3. Klarenbach $S$ and Manns B. Economic evaluation of dialysis therapies. Semin Nephrol 2009 Sep; 29(5): 524-532.

4. Barnieh L, King-Shier K, Hemmelgarn B et al. Views of Canadian patients on or nearing dialysis and their caregivers: a thematic analysis. Can J Kidney Health Dis. 2014, 1:4. 5. Mathew AT, Park J, Sachdeva M et al. Barriers to Peritonea Dialysis in aboriginal patients. Can J Kidney Health Dis. 2018; 5:1-9.

6. Chan CT, Wallace E, Golper TA et al. Exploring barriers and potential solutions in home dialysis: an NKF-KDOQI Conference outcomes report. Am J kidney 2018; 73(3): 363-371. 